\title{
Transformed Pedagogical Environment: Humanoids for social skilling of mentally challenged children
}

\author{
Rugayah Hashim ${ }^{1 *}$, Sabarinah Sh. Ahmad ${ }^{2}$, Amily Fikri Aziz ${ }^{3}$, Fazah Akhtar Hanapiah 4 \\ ${ }^{1}$ Faculty of Administrative Science \& Policy Studies, ${ }^{2}$ Faculty of Architecture, Planning \& Surveying, \\ ${ }^{3}$ Faculty of Business Management, Universiti Teknologi MARA, 40450 Shah Alam, Selangor, Malaysia \\ ${ }^{4}$ Faculty of Medicine, Universiti Teknologi MARA, Sg. Buloh, 47000, Selangor, Malaysia
}

\begin{abstract}
The purpose of the paper is to describe the transformed pedagogical environment in Malaysia with regards to mentally challenged children. Through interviews with teachers and parents of children schooled at the special, integrative classes in Shah Alam, Selangor, Malaysia, the results indicated non-readiness for the teachers and the parents to embrace the assistive technology, the humanoids. Besides the high cost of purchasing the humanoid for each child to be placed at home, social skilling these special children requires human touch. Cultural, and religious aspects abound that negates the progress of pedagogy using humanoids.
\end{abstract}

eISSN: 2398-4287@ 2016. The Authors. Published for AMER ABRA by e-International Publishing House, Ltd., UK. This is an open access article under the CC BY-NC-ND license (http://creativecommons.org/licenses/by-nc-nd/4.0/). Peer-review under responsibility of AMER (Association of Malaysian EnvironmentBehaviour Researchers), ABRA (Association of Behavioural Researchers on Asians) and cE-Bs (Centre for Environment-Behaviour Studies), Faculty of Architecture, Planning \& Surveying, Universiti Teknologi MARA, Malaysia.

http://dx.doi.org/10.21834/e-bpj.v1i1.187

Keywords: pedagogy, children, humanoids, social skill

\section{Introduction}

The new millenium has propeled technology-driven revolution with dramatic success particularly in the medical field. Solution and new discoveries to the health industry has never been more emphasized to assist mankind achieve physical, mental and emotional well-being and good quality of life. Disabled children such as those that are mentally challenged are on the increase in tandem with the population explosion globally (Weintraub \& Payne, 2013).

\footnotetext{
* Corresponding author. Tel.: +603-55444158

E-mail address: Dr-Gy@outlook.com
}

eISSN: 2398-4287@ 2016. The Authors. Published for AMER ABRA by e-International Publishing House, Ltd., UK.. This is an open access article under the CC BY-NC-ND license (http://creativecommons.org/licenses/by-nc-nd/4.0/). Peer-review under responsibility of AMER (Association of Malaysian EnvironmentBehaviour Researchers), ABRA (Association of Behavioural Researchers on Asians) and CE-Bs (Centre for Environment-Behaviour Studies), Faculty of Architecture, Planning \& Surveying, Universiti Teknologi MARA, Malaysia. 
In fact, the trend on the prevalence of children with autism has shown a marked increase in the United States alone (Braun et al., 2015). With the increasing numbers, there is a need to increase the number of special education teachers to meet the demand. Nevertheless, with innovative assistive technologies, special education needs have been given a new lease in teaching and training for these gifted children particularly for social skills training (Fisher \& Spencer, 2015).

The use of humanoids for educating mentally or intellectually challenged children has transformed the pediatric environment (Prendergast, Ma, \& Ming, 2015) in developed nations. Such transformational innovation has also impacted Malaysia, a developing country. Such advances in helping these special children should be shared so that the knowledge gap among practitioners are narrowed, that is, to reduce the lag time on new technology developments between developed nations and developing countries. Hence, the purpose of this paper is to describe these transformations within the scope of public schools with special-needs classes. In particular, the paper will provide highlights on the perceptions and readiness of teachers and parents of the mentally and intellectually challenged children for this innovative technological transformation.

\section{Conceptual Background and Literature Review}

The motivation for the fundamental research study involving humanoids, is the extension of a theory; the cognitive behavioral theory relative to the social skilling of mentally-challenged children. For this paper, only those children with learning disabilities are segregated for better focus. Nonetheless, from literature ferreted, humanoid robotics research have spilled-over into perception studies, processing and action studies that are embodied in anthropomorphic form in order to emulate some subset of the physical, cognitive, and social dimensions of the human body and experience (Swinson \& Bruemmer, 2000). Specifically, several studies have shown the positive effect of humanoid on autistic children. For example, humanoid robots have improvised the emotional and communication deficit (Hoa \& Cabibihan, 2012; Jordan, King, Hellersteth, Wiren, \& Mulligan, 2013) and, social and behavioral skill of autistic children (Robins \& Dautenhahn, 2010; Robins et al., 2012). Humanoid robots have also been shown in the provision of economic benefits to teachers and parents (Dautenhahn, 2003) of autistic children. However, evidences on the socio-economic benefits in social-skill training on brain-impaired children have been lacking. In the realms of pedagogy, every child should been given the chance to be educated no matter the circumstances of the disabilities.

Anyhow, the introduction of new systems, particularly an assistive technology like humanoids, the impact to people is varied (Diehl, Schmitt, Villano, \& Crowell, 2012). This includes environmental behaviour, wellness, lifestyle as well as economic positions. Investigations on the on implications of brain impairment treatment applications on human in terms of their wellness and their environmental behaviour are proposed. It incorporates the social, cultural, economic, ethical and spiritual implications of the use of technology in treating brain impairment that provide insights and guidelines to curtail unanticipated social and economic problems. From past studies, humanoid robots have been shown to have a positive effect on the social-cognitive behavior of brain-impaired children. Several studies have shown the positive effect of humanoid on autistic child. For example, humanoid robots have improvised the emotional, communication deficit, social and behavioral skill of autistic child. Within the medical, psychological and pediatric research, various mental disabilities have been identified such as autism, dyslexia, slow learners, etc. (Tanaka \& Kimura, 2010). However, the extent of developmental rehabilitation has been slow to progress. As a result, the intellectual abilities of these special children are dependent on new methods in assistive technologies.

Nonetheless, previous studies in developed nations have shown the positive benefits of engaging humanoid robots in education and social skilling of mentally challenged children (Costa, Lehmann, Dautenhahn, Robins, \& Soares, 2015). This technology in turn, have evidenced economic benefits to the teachers and parents of autistic children. However, evidences on paired socio-economic benefits in social-skill training on brain-impaired children have been lacking. The fundamental study will evaluate the socio-economic benefits of humanoid-assisted social skills training of brain-impaired children. From the literature reviewed, content analyses on humanoid-mediated research articles within the scope of social science and children have been limited.

Consequently, by applying the cognitive behavioral theory in humanoid research of brain impaired children, the theory will be extended to encompass emergent factors surrounding socio-economic and spiritual variables. The implications of this study 
are in tandem within the four pillars of national transformation as well as the government agenda listed under the National Key Result Areas, the Strategic Reform Initiatives. The expected outcomes of this study would generate a policy surrounding the new, extended theory on humanoid research relative to the cognitive behavioral concepts involving children, built within the foundations of social, cultural, economic, ethics and spiritual values.

\section{Methodology}

For this fundamental, social science study, the research methodology employs a qualitative approach including insider's observations of a case study. This method has been shown to provide credible results as rigor has not been compromised (Coles, 2015). Furthermore, Bonner and Tolhurst (2002) identified three key advantages of being an insider-researcher:

(a) having a greater understanding of the culture being studied;

(b) not altering the flow of social interaction unnaturally; and

(c) having an established intimacy which promotes both the telling and the judging of truth.

In justifying the suitability of employing an insider study, Coles (2015) stated that this method can actually uncover a unique perspective of the issues that directly affect the mentally or intellectually-impaired children. In addition, as a case study, the focus is more pronounced and narrowed as daily tracking of the units of analysis are observed. Hence, for this case study, a primary school with integration classes for special children was identified. All the pupils attending these integration classes have various impairments that require intimate and personal pedagogy. As previously mentioned, the pupils suffer from various levels of autism, down syndrome, dyslexia and slow learning.

For primary data collection, interviews were conducted with the teachers working at the integration classes. A sample size of 20 teachers were pre-determined and the interviews were conducted through the use of a semi-structured guideline. For both the conduct and completion of these methods, the timeframe was two years. In analyzing the interviews transcripts, pattern coding and content analyses (Miles \& Huberman, 1994) were done manually as well as through the use of the qualitative software, NVivo. Bearing in mind that this is a fundamental research, the resultant analyses was the emergent framework. Also, the use of a narrative approach that combined interviews and observational data collected over a specified period provides for a holistic understanding (Prendergast et al., 2015) on the use of humanoids, for social skill training and augmentation.

\section{Findings}

As previously stated in the methodology section, the qualitative analyses of the interviews were undertaken. From the 20 teachers identified, data saturation was attained at the seventh interviewee. All responses from the last interviewee mirrored the responses from the other six. The narrative findings will be described according to the questions in the guideline:

For question one on whether the teachers know what a humanoid is, none were able to respond correctly until the word "robot" was inserted. However, the description of the robot or humanoid is based on the teachers' exposure to science fiction movies such as RoboCop, Transformers, etc. From the varied responses and curiosities, the second question was posed that is, if the teachers are aware of humanoids as an assistive technology in pedagogy for mentally and intellectually-challenged children. All the teachers gave a negative response but followed with opinions that such an innovative technology may have positive implications to the children depending on which subject that the humanoids will be used for. For subjects that require rote learning and repetitive enunciations for memorizing words to pictures, for example, then the humanoids would prove to be helpful.

It is important to note at this point that the insider research was undertaken as the spontaneous responses from the interviewees were based on their experience, knowledge and exposure to teaching and learning for mentally and intellectuallychallenged primary school children. Nonetheless, a senior teacher said that robots will aid in religious subjects that require a lot 
of memorizing the verses from the Quran. This is because, the repetitive nature of the learning process would take a toll on the teacher, but the humanoid can continue to repeat the verses like a tape recorder or CD player.

Also, the children's span of attention may dwindle after twenty minutes of repetitive learning and will start to show their boredom. In this case, a human teacher would be able to detect the boredom through the children's body language. Hence, the question, "Would the humanoid be able to do the same?" Another useful role of the humanoid would be for social skill training such as using spoons for eating. However, culture and tradition of the Malays when it comes to table manners would not work well as we eat with our hands rather than use silverware. The humanoids would not be able to show the correct way to scoop rice and bring it to the mouth. Besides table manners, the humanoids would prove to be ideal in showing how to kick a ball, for example, for the physical activity class.

For the third question of whether the teachers have seen a humanoid before, mixed responses were received of which three gave a definite yes while the remaining four were uncertain. This was detected in their ambiguous description of a humanoid. When prodded further, the teachers admitted that their descriptions are based on movies and comic books that they accidentally came across from time to time. Yet, they are ignorant to the actual, visual description of a humanoid is Henceforth, a picture of the humanoids used in the Center for Humanoid Robots and Bio-sensing (HuRoBs), Faculty of Mechanical Engineering, University Teknologi MARA were shown to the teachers (see Fig. 1). Surprised exclamations were noted from all seven of them as two commented on the almost-close resemblance of the Nao humanoid to that of Honda's Asimo robot.

Anyhow, upon seeing the picture of the Nao humanoid, the common comments from the seven teachers were that Nao looks cute and would certainly make the pupils excited. Their next question to the researcher was the size of the humanoid. When they were informed that the Nao humanoid is about two feet tall, a crestfallen look was obvious on their expressions. The automatic responses were, "It is small". Their next response was to request that an actual Nao be brought to the school and provide demonstrations on the abilities of Nao.

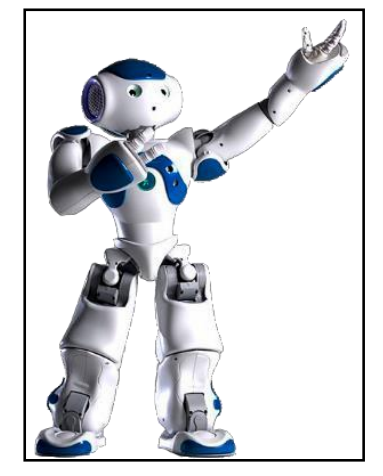

Fig. 1. The Nao Humanoid

Moving on, for the fourth question whether Nao can replace teachers in future, a mixed reaction was observed, but the responses received were practical and logical. In relating such a transformation in the pedagogy environment involving pupils who are mentally or intellectually challenged, such a plan may take time. Assimilation of a non-human educator compared to a human being may not augur well in Malaysia. Outcomes and findings from such research projects will have to be approved by policy makers and other stakeholders, particularly, the parents and guardians.

For the last question on whether the pupils will accept the humanoids in their daily learning, mixed responses were observed but it was consensually noted that pupils with brain challenges may look at the humanoids as toys rather than a pedagogical tool or enabler. Maybe in a decade, the education environment for children may evolve to such an extent that robots could replace 
humans but the disadvantages of machines over humans were noted. The emotional and psychological aspects of mentally challenged children cannot be replaced by machines.

Hence, the next section will discuss the implications of such a drastic transformation in pedagogy in the future.

\section{Implications and Discussions}

As indicated from the interview responses the use of humanoids to replace teachers in the pedagogical environment involving disabled and mentally-challenged children were not readily acceptable at this time. Such technological revolution also have cultural and religious implications. In a country like Malaysia where religion rules, the intrusion of a non-human being in their children's lives will have to show sufficient evidence of progress. However, in the pedagogical environment, the assistive technology may be given a chance as the children are not wholly governed 7/24 but will have teachers and family members to cater to their emotional and psychological needs. That is the main advantage compared to a humanoid.

\section{Conclusion}

As a conclusion, the findings showed that the teachers at the integration classes are unaware of and pessimistic on humanoids replacing humans for pedagogical augmentation of social skills training among mentally or intellectually challenged children. Such advanced assistive technology for Malaysia, at least, require gradual introduction with proof of positive developments before humanoids can be accepted for teaching and learning in primary schools. Ninety-five percent of the respondents opined the actual readiness in six years' time which would be in the year 2020. Furthermore, the implications of the study showed that teachers who are involved with mentally challenged children should be exposed to the innovative transformation, that is, using humanoids to enhance the social skills of these special children especially for repetitive behaviors which to the teachers, require extreme patience and time. Since this is a case study research, it is recommended that the scope for further investigation should include other special-needs classes and schools in Malaysia. Lastly, the findings from this study would significantly impact the special-education schools and private institutions that deal with mentally and intellectuallychallenge children. The impact of humanoids in education is in tandem with the government's National Key Result Area (NKRA), in assisting the disadvantaged individuals.

\section{Acknowledgements}

The study is made possible through research funding by the Ministry of Education, Malaysia under the Niche Research Grant Scheme (NRGS 13/2013). Due acknowledgement is also accorded to the teachers at the integration classes of Raja Muda Primary School, Section 7, Shah Alam, Selangor.

\section{References}

Bonner, A., \& Tolhurst, G. (2002). Insider-outsider perspectives of participant observation. Nurse researcher, 9(4), 7-19.

Braun, K. V. N., Christensen, D., Doernberg, N., Schieve, L., Rice, C., Wiggins, L., . . Yeargin-Allsopp, M. (2015). Trends in the Prevalence of Autism Spectrum Disorder, Cerebral Palsy, Hearing Loss, Intellectual Disability, and Vision Impairment, Metropolitan Atlanta, 1991-2010. PLoS ONE, 10(4). doi: 10.1371/journal.pone.0124120

Coles, B. (2015). A "Suitable Person': an "insider' perspective. British Journal of Learning Disabilities, 43(2), 135-141. doi: 10.1111/bld.12125

Costa, S., Lehmann, H., Dautenhahn, K., Robins, B., \& Soares, F. (2015). Using a Humanoid Robot to Elicit Body Awareness and Appropriate Physical Interaction in Children with Autism. International journal of social robotics, 7(2), 265-278. doi: 10.1007/s12369-014-0250-2

Dautenhahn, K. (2003). Roles and functions of robots in human society: Implications from research in autism therapy. Robotica, 21(4), 443-452.

Diehl, J. J., Schmitt, L. M., Villano, M., \& Crowell, C. R. (2012). The clinical use of robots for individuals with Autism Spectrum Disorders: A critical review. Research in Autism Spectrum Disorders, 6(1), 249-262. doi: 10.1016/j.rasd.2011.05.006

Fisher, L., \& Spencer, F. (2015). Children's Social Behaviour for Learning (SBL): reported and observed social behaviours in contexts of school and home. Social Psychology of Education, 18(1), 75-99. doi: 10.1007/s11218-014-9276-4

Hoa, T. D., \& Cabibihan, J. J. (2012). Cute and soft: Baby steps in designing robots for children with autism.Workshop at SIGGRAPH Asia, Singapore. 
Jordan, K., King, M., Hellersteth, S., Wiren, A., \& Mulligan, H. (2013). Feasibility of using a humanoid robot for enhancing attention and social skills in adolescents with autism spectrum disorder. International Journal of Rehabilitation Research, 36(3), 221-227. doi: 10.1097/MRR.0b013e32835d0b43

Miles, M. B., \& Huberman, A. M. (1994). Qualitative Data Analysis: An Expanded Sourcebook (2nd ed.). Thousand Oaks, CA: Sage.

Prendergast, G., Ma, S., \& Ming, E. T. Y. (2015). Surprisingly complex life: Sue Leung's story. Asia-Pacific Psychiatry, 7(2), 190-196. doi: 10.1111/appy.12121

Robins, B., \& Dautenhahn, K. (2010) Developing play scenarios for tactile interaction with a humanoid robot: A case study exploration with children with autism. Vol. 6414 LNAI (pp. 243-252).

Robins, B., Dautenhahn, K., Ferrari, E., Kronreif, G., Prazak-Aram, B., Marti, P., . . Laudanna, E. (2012). Scenarios of robot-assisted play for children with cognitive and physical disabilities. Interaction Studies, 13(2), 189-234.

Swinson, M. L., \& Bruemmer, D. J. (2000). Expanding Frontiers of Humanoid Robotics (pp. 12-17). IEEE Intelligent Systems: IEEE.

Tanaka, F., \& Kimura, T. (2010). Care-receiving robot as a tool of teachers in child education. Interaction Studies, 11(2), 263.

Weintraub, K., \& Payne, C. (2013). Autism numbers rise in latest count. USA today. Retrieved from http://www.usatoday.com/story/news/nation/2013/03/20/children-autism-frequency/2000131/ 